\title{
Desempenho e Características da Carcaça de Tourinhos Santa Gertrudes Confinados, Recebendo Dietas com Alto Concentrado e Níveis Crescentes de Polpa Cítrica Peletizada ${ }^{1}$
}

\author{
Wignez Henrique ${ }^{2}$, Alexandre Amstalden Moraes Sampaio ${ }^{3}$, Paulo Roberto Leme ${ }^{4}$, Dante \\ Pazzanese Duarte Lanna ${ }^{5}$, Guilherme Fernando Alleoni ${ }^{6}$, José Luiz Viana Coutinho Filho ${ }^{7}$
}

\begin{abstract}
RESUMO - O experimento foi desenvolvido com o objetivo de avaliar o efeito da substituição do milho pela polpa cítrica peletizada sobre o desempenho e as características da carcaça de tourinhos Santa Gertrudes confinados. Vinte e oito animais, com nove meses de idade e peso inicial de $277 \mathrm{~kg}$, foram confinados em baias individuais. O período experimental foi de 92 dias, após 21 dias de adaptação. Os animais receberam dietas contendo $20 \%$ da matéria seca como silagem de milho, com $40 \%$ de grãos. Foram testados os níveis de 0 , 25, 40 e 55\% de participação da polpa cítrica peletizada na matéria seca da dieta. Não houve efeito do nível de polpa cítrica na dieta sobre ganho de peso, ingestão diária de matéria seca, eficiência alimentar, rendimento de carcaça, área de olho de lombo e peso da gordura renalpélvica-inguinal. Os pesos do fígado e da carcaça foram significativamente maiores com o aumento da polpa cítrica na dieta, que também determinou decréscimo linear na espessura de gordura sobre a 12 a costela. $\mathrm{O}$ pH das fezes foi semelhante entre os níveis de participação da polpa cítrica. Não foi verificada a ocorrência de abscessos no fígado em nenhum tratamento, apesar da dieta conter alto teor de concentrado. A polpa cítrica peletizada pode compor até 55\% da matéria seca de dietas, substituindo o milho em grão, para tourinhos em terminação recebendo altos níveis de concentrado, apenas com diminuição da espessura de gordura.
\end{abstract}

Palavras-chave: espessura de gordura, ganho de peso, ganho de peso de carcaça, ganho de peso vazio, pH fezes, rendimento de carcaça

\section{Feedlot Performance and Carcass Characteristics of Santa Gertrudis Bulls, Fed High Concentrate Diets with Increasing Levels of Dehydrated Citrus Pulp Pellets}

\begin{abstract}
The experiment was developed to evaluate the effect of the replacement of corn grain by dehydrated citrus pulp pellets on the performance and carcass characteristics of Santa Gertrudis young bulls fed high concentrate diets. Twenty-eight bulls, with average age of nine months and an initial weight of $277 \mathrm{~kg}$, were kept in individual pens and fed during 92 days, after 21 days of adaptation. The animals were fed a diet with $20 \%$ of the dry matter as corn silage, with $40 \%$ of grain. Treatments evaluated included levels of $0,25,40$ and $55 \%$ of dehydrated citrus pulp pellets in the dry matter diet. There was no effect of citrus pulp level on the average daily gain, daily dry matter intake, feed efficiency, carcass dressing, Longissimus muscle area and the kidney, pelvic and inguinal fat. The increasing level of citrus pulp on the diet decreased linearly the backfat thickness and increased linearly the liver weight and carcass weight. The feces $\mathrm{pH}$ was similar for all the citrus pulp levels. Liver abscess were not detected, although the diet had high concentrate level. The dehydrated citrus pulp pellets can compound until $55 \%$ of dry matter diet, replacing corn grain to finishing young bulls fed high concentrate diets, with a small decrease in subcutaneous fat.
\end{abstract}

Key Words: carcass dressing, carcass weight gain, empty body weight gain, fat thickness, feces pH, liveweight gain

\section{Introdução}

A polpa cítrica peletizada é um subproduto da produção de suco de laranja e está disponível no mercado interno, nos últimos anos, a um preço geralmente inferior ao milho em grão. Pode ser utilizada na alimentação de ruminantes, principalmente como componente energético da dieta, e a sua oferta coincide com o período de escassez de forragem.

Utilizada como substituto do milho desintegrado com palha e sabugo, Velloso et al. (1974) encontraram melhoras significativas no ganho de peso e na conversão alimentar para tourinhos mestiços confinados, recebendo dietas com até $30 \%$ de polpa e $45 \%$ de concentrado na matéria seca. Trabalhando com tourinhos Canchim, Esteves et al. (1987) obtiveram

\footnotetext{
1 Parte da Tese de Doutoramento da primeira autora junto a FCAV/UNESP, Jaboticabal, SP; financiado pela Fapesp.

2 Pesquisadora Científica, Instituto de Zootecnia, São José do Rio Preto, SP, Bolsista CNPq (wignez@terra.com.br).

3 Professor, Depto. Zootecnia/FCAV/UNESP, Jaboticabal, SP, Bolsista CNPq (sampaio@fcav.unesp.br).

4 Professor, Depto. Zootecnia/FZEA/USP, Pirassununga, SP, Bolsista CNPq (prleme@usp.br).

5 Professor, Depto. Zootecnia/ESALQ/USP, Piracicaba, SP, Bolsista CNPq (dplanna @ esalq.usp.br).

6 Pesquisador Científico, Instituto de Zootecnia, Nova Odessa, SP (alleoni@izsp.br).

7 Pesquisador Científico, Instituto de Zootecnia, São José do Rio Preto, SP (updmirassol@apta.sp.gov.br)
} 
aumento do ganho de peso com 50\% de substituição, mas não para a substituição total, sendo que o concentrado participou como $66 \%$ da dieta. Os autores recomendaram a substituição de 50\% do milho desintegrado com palha e sabugo pela polpa de citros.

Comparando a polpa cítrica com o melaço de cana-de-açúcar na engorda de vacas, Brown \& Johnson (1991) não encontraram diferenças para ganho de peso $(0,70 \mathrm{~kg} / \mathrm{dia})$, consumo de alimentos, peso e rendimento de carcaça, espessura de gordura, área de olho de lombo e gordura renal-pélvica-inguinal.

A literatura aponta teores de aproximadamente $80 \%$ de nutrientes digestíveis totais para a polpa cítrica, indicando teor energético $13 \%$ inferior ao do milho, conforme tabelas de composição de alimentos do NRC (1996). Entretanto, a polpa cítrica parece proporcionar melhor padrão de fermentação ruminal que o milho, devido ao menor conteúdo de amido e à maior concentração de pectinas (Van Soest, 1994). Problemas digestivos, como acidose, laminite, baixo consumo de alimentos e abscessos de fígado, podem ocorrer quando se utilizam dietas com altas proporções de carboidratos fermentescíveis, principalmente quando o maior componente desses carboidratos é o amido, mas não fica eliminada essa possibilidade com o uso de pectinas (Woody et al., 1983).

Mesmo assim, os resultados da literatura comparando a polpa cítrica e o milho em grão não têm sido consistentes quanto ao desempenho e às características da carcaça de bovinos. Vijchulata et al. (1980), trabalhando com dietas com $85 \%$ de concentrado, não observaram diferenças no ganho de peso $(1,06 \mathrm{~kg} / \mathrm{dia})$ quando a polpa cítrica participou como $40 \%$ da matéria seca da dieta; o rendimento de carcaça e o grau de marmorização também não apresentaram diferenças. De forma semelhante, utilizando $60 \%$ da dieta na forma de polpa de citros, esses mesmos autores não encontraram diferença para ganho de peso, consumo de matéria seca, conversão alimentar e características da carcaça. Prado et al. (2000) também não encontraram nenhuma alteração de ganho de peso, consumo, conversão alimentar, rendimento de carcaça, gordura de cobertura e área de olho de lombo de tourinhos cruzados Nelore x Angus, quando substituíram 40, 60, 80 e $100 \%$ do milho pela polpa cítrica em dietas com cerca de $50 \%$ de concentrado.

Com novilhos da raça Nelore, Sampaio et al. (1984) não encontraram diferenças no ganho de peso, ao redor de $0,95 \mathrm{~kg} / \mathrm{dia}$, quando utilizaram polpa de citros desidratada, milho em grão ou a mistura deles em igual proporção, como componentes energéticos do concentrado, em dietas com $60 \%$ de concentrado. Por outro lado, foram encontradas diferenças na conversão alimentar, que piorou com o aumento da polpa de citros na dieta.

Contrariamente, Henrique et al. (1998) concluíram que, em dietas com baixa proporção de concentrado (20\% da matéria seca), o milho pode ser substituído integralmente pela polpa de citros peletizada para bovinos jovens confinados, sem alterações do desempenho animal e das características da carcaça. Nessas condições, os resultados médios foram: para ganho de peso de 1,02 kg/dia; 6,02 kg/dia de matéria seca consumida; $0,17 \mathrm{~kg}$ de ganho de peso $/ \mathrm{kg}$ matéria seca ingerida; $50,8 \%$ de rendimento de carcaça; $3,7 \mathrm{~mm}$ de espessura de gordura; e $54 \mathrm{~cm}^{2}$ de área de olho de lombo. Em rações com $80 \%$ de concentrado, a substituição do milho pela polpa de citros reduziu consideravelmente o consumo de matéria seca e o ganho de peso, e prejudicou algumas variáveis avaliadas na carcaça. Os autores justificaram esses resultados devido ao teor de cálcio do lote da polpa cítrica utilizada, determinando uma porcentagem de cálcio na dieta próxima ao limite máximo recomendado de 2\% (NRC, 1996).

Objetivou-se com o presente trabalho avaliar os efeitos de níveis de inclusão da polpa cítrica, substituindo o milho em grão, sobre o desempenho e as características da carcaça de tourinhos Santa Gertrudes confinados, recebendo dietas com elevada proporção de concentrado.

\section{Material e Métodos}

O experimento foi conduzido no Instituto de Zootecnia de São José do Rio Preto, SP, com animais do rebanho do próprio Instituto, os quais foram mantidos confinados em baias coletivas após a desmama.

Foram selecionados 28 tourinhos Santa Gertrudes, com nove meses de idade, que permaneceram confinados em baias individuais, com cerca de $6 \mathrm{~m}^{2}$, parcialmente cobertas e cimentadas.

$\mathrm{O}$ delineamento experimental utilizado foi $\mathrm{em}$ blocos ao acaso, sendo os blocos formados a partir do peso dos animais e alocados aleatoriamente na instalação. Os animais foram mantidos confinados durante 113 dias, sendo os primeiros 21 dias considerados como adaptação.

A silagem de milho com $40 \%$ de grãos foi utilizada 
como volumoso e representou $20 \%$ da matéria seca da dieta. Foram avaliados quatro tratamentos, ou seja, quatro dietas com diferentes participações de polpa cítrica peletizada $(0,25,40$ e $55 \%$ da matéria seca), substituindo o milho em grão. A composição dessas dietas está apresentada na Tabela 1, tendo sido ajustadas pelo modelo Cornell Net Carbohydrate and Protein System - CNCPS (Sniffen et al., 1992) para atender às exigências de proteína degradável no rúmen e proteína metabolizável para a categoria animal utilizada, bem como às exigências de aminoácidos e peptídeos das bactérias do rúmen.

Assim, os tratamentos consistiram na substituição de $0,38,62$ e $86 \%$ do milho, em relação ao tratamento sem polpa cítrica, respectivamente para os tratamentos $0,25,40$ e $55 \%$ de participação da polpa cítrica na matéria seca da dieta.

Os alimentos foram fornecidos na forma de ração completa, em duas refeições diárias, e os animais tinham livre acesso à água. A quantidade de volumoso foi corrigida diariamente, e a de concentrado, semanalmente, permitindo-se sobras em torno de $10 \%$. Os

Tabela 1 - Composição das dietas experimentais (porcentagem da matéria seca)

Table 1 - Composition of the experimental diets (percentage of the dry matter)

\begin{tabular}{|c|c|c|c|c|}
\hline \multirow[t]{2}{*}{$\begin{array}{l}\text { Ingredientes } \\
\text { Ingredients }\end{array}$} & \multicolumn{4}{|c|}{$\begin{array}{c}\text { Tratamentos - Porcentagem de polpa cítrica } \\
\text { Treatments - Percentage of citrus pulp }\end{array}$} \\
\hline & 0 & 25 & 40 & 55 \\
\hline $\begin{array}{l}\text { Silagem de milho } \\
\text { Corn silage }\end{array}$ & 20,00 & 20,00 & 20,00 & 20,00 \\
\hline $\begin{array}{l}\text { Polpa cítrica } \\
\text { Citrus pulp }\end{array}$ & 0,00 & 25,00 & 40,00 & 55,00 \\
\hline $\begin{array}{l}\text { Milho em grão moído } \\
\text { Corn ground grain }\end{array}$ & 67,40 & 41,45 & 25,65 & 9,35 \\
\hline $\begin{array}{l}\text { Farelo de soja } \\
\text { Soybean meal }\end{array}$ & 10,20 & 12,20 & 13,00 & 14,10 \\
\hline $\begin{array}{l}\text { Fosfato bicálcico } \\
\text { Dicalcium phospate }\end{array}$ & 0,00 & 0,20 & 0,30 & 0,50 \\
\hline $\begin{array}{l}\text { Uréia } \\
\text { Urea }\end{array}$ & 0,30 & 0,30 & 0,30 & 0,30 \\
\hline $\begin{array}{l}\text { Monensina sódica } \\
\text { Sodium monensin }\end{array}$ & 0,02 & 0,02 & 0,02 & 0,02 \\
\hline $\begin{array}{l}\text { Sulfato de amônio } \\
\text { Ammonium sulfate }\end{array}$ & 0,03 & 0,03 & 0,03 & 0,03 \\
\hline $\begin{array}{l}\text { Calcário calcítico } \\
\text { Limestone }\end{array}$ & 1,10 & 0,00 & 0,00 & 0,00 \\
\hline $\begin{array}{l}\text { Sal mineral } \\
\text { Mineral salt }\end{array}$ & 0,70 & 0,70 & 0,70 & 0,70 \\
\hline $\begin{array}{l}\text { Cloreto de potássio } \\
\text { Potassium chloride }\end{array}$ & 0,25 & 0,10 & 0,00 & 0,00 \\
\hline $\begin{array}{l}\text { Valores estimados }{ }^{2} \\
\text { Estimated values }^{2}\end{array}$ & & & & \\
\hline $\begin{array}{l}\text { Nutrientes digestíveis totais, } \% \\
\text { Total digestible nutrients, } \%\end{array}$ & 82,73 & 81,57 & 80,17 & 78,94 \\
\hline $\begin{array}{l}\text { Energia metabolizável, Mcal/kg } \\
\text { Metabolizable energy, Mcal/kg }\end{array}$ & 2,99 & 2,95 & 2,90 & 2,85 \\
\hline $\begin{array}{l}\text { Proteína bruta, \% MS }{ }^{1} \\
\text { Crude protein, \% DM }\end{array}$ & 13,60 & 13,70 & 13,60 & 13,60 \\
\hline $\begin{array}{l}\text { Cálcio, } \% \mathrm{MS}^{1} \\
\text { Calcium, \% DM }\end{array}$ & 0,43 & 0,56 & 0,86 & 1,18 \\
\hline $\begin{array}{l}\text { Fósforo, \% MS }{ }^{1} \\
\text { Phosphorus, \% DM }{ }^{1}\end{array}$ & 0,33 & 0,34 & 0,33 & 0,35 \\
\hline
\end{tabular}

R. Bras. Zootec., v.33, n.2, p.463-470, 2004 
cochos foram limpos duas vezes por semana, desprezando-se as sobras. Semanalmente, foram determinados os teores de matéria seca dessas sobras e dos alimentos oferecidos para ajuste da relação volumoso:concentrado.

Os animais foram pesados no início do período de adaptação, no início e no final do período experimental, e periodicamente, após jejum completo de $18 \mathrm{~h}$. Foram obtidas as variáveis peso inicial e final, ganho de peso, consumo de matéria seca diário e em relação ao peso e eficiência alimentar. Na última pesagem, foram também coletadas amostras das fezes dos animais para medida do $\mathrm{pH}$, como indicador da digestão de amido (Wheeler \& Noller, 1977).

No final do período experimental, todos os animais foram abatidos em frigorífico comercial e feitas medidas na carcaça para obtenção das seguintes variáveis: peso e rendimento de carcaça, área de olho de lombo entre a $12^{\underline{a}}$ e a $13^{\underline{a}}$ costelas, espessura de gordura sobre a $12^{\mathrm{a}}$ costela, peso do fígado, e peso da gordura renal-pélvica-inguinal. A área de olho de lombo e a espessura de gordura foram medidas na carcaça após resfriamento durante 24 horas, sendo a área de olho de lombo medida com auxílio da régua quadriculada. Foi também averiguada a ocorrência de abscessos no fígado, segundo metodologia descrita pela Elanco (1974).

Todas as variáveis obtidas foram analisadas (SAS, 1996) quanto à normalidade de distribuição pelo teste de Shapiro-Wilk, e quanto à homogeneidade da variância pelo teste de Bartlett, tendo sido considerado o nível de 5\% de probabilidade para significância.

Após essas análises preliminares tendo sido satisfatórias, os resultados foram analisados estatisticamente por regressão polinomial, considerando-se blocos ao acaso, com sete repetições, e quatro tratamentos $(0,25,40$ e $55 \%$ de polpa cítrica peletizada na matéria seca da dieta). O coeficiente de determinação foi calculado dividindo-se a somatória da soma de quadrados da regressão de menor grau até a soma de quadrados da regressão de grau significativo, dividida pela soma de quadrados de tratamentos.

\section{Resultados e Discussão}

A composição químico-bromatológica média do volumoso e dos concentrados utilizados neste experimento encontra-se na Tabela 2. A polpa cítrica peletizada utilizada neste experimento apresentou $85,46 \%$ de matéria seca e a seguinte composição,

Tabela 2 - Composição químico-bromatológica da silagem de milho e dos concentrados utilizados

Table 2 - Chemical composition of the corn silage and concentrates

\begin{tabular}{|c|c|c|c|c|c|}
\hline \multirow[t]{2}{*}{$\begin{array}{l}\text { Componentes } \\
\text { Components }\end{array}$} & \multirow{2}{*}{$\begin{array}{c}\text { Silagem } \\
\text { milho } \\
\text { Corn silage }\end{array}$} & \multicolumn{4}{|c|}{$\begin{array}{c}\text { Concentrados - Porcentagem de polpa cítrica } \\
\text { Concentrates - Percentage of citrus pulp }\end{array}$} \\
\hline & & 0 & 25 & 40 & 55 \\
\hline $\begin{array}{l}\text { Matéria seca, } \% \\
\text { Dry matter, } \%\end{array}$ & 35,02 & 87,87 & 86,65 & 86,78 & 85,42 \\
\hline $\begin{array}{l}\text { Proteína bruta } \\
\text { Crude protein }^{1}\end{array}$ & 8,59 & 15,42 & 15,13 & 14,96 & 15,22 \\
\hline $\begin{array}{l}\text { Extrato etéreo }^{1} \\
\text { Ether extract }^{1}\end{array}$ & 2,78 & 3,15 & 2,98 & 2,86 & 2,66 \\
\hline $\begin{array}{l}\text { Matéria mineral }{ }^{1} \\
\text { Ash }^{1}\end{array}$ & 3,15 & 4,02 & 4,35 & 4,92 & 6,50 \\
\hline $\begin{array}{l}\text { Matéria orgânica }{ }^{1} \\
\text { Organic matter }^{1}\end{array}$ & 96,85 & 95,98 & 95,65 & 95,08 & 93,50 \\
\hline $\begin{array}{l}\text { Fibra em detergente neutro }{ }^{1} \\
\text { Neutral detergent fiber }\end{array}$ & 53,67 & 38,80 & 35,66 & 32,45 & 30,28 \\
\hline $\begin{array}{l}\text { Fibra em detergente ácido }{ }^{1} \\
\text { Acid detergent fiber }^{1}\end{array}$ & 28,46 & 4,32 & 8,89 & 11,43 & 14,72 \\
\hline $\begin{array}{l}\text { Hemicelulose }^{1} \\
\text { Hemicellulose }^{1}\end{array}$ & 25,21 & 34,48 & 26,77 & 21,02 & 15,56 \\
\hline $\begin{array}{l}\text { Lignina }^{1} \\
\text { Lignin }^{1}\end{array}$ & 7,64 & 1,76 & 1,98 & 2,74 & 3,05 \\
\hline
\end{tabular}

1 Porcentagem da matéria seca.

1 Percent of dry matter. 
como porcentagem da matéria seca: 5,99 de proteína bruta; 1,48 de extrato etéreo; 4,67 de matéria mineral; 19,30 de fibra em detergente neutro; 1,22 de cálcio; e 0,09 de fósforo.

O peso inicial, o peso final, o ganho de peso diário, a ingestão de matéria seca e a eficiência alimentar estão apresentados na Tabela 3.

A substituição do milho em grão pela polpa cítrica peletizada, como fonte de energia, não alterou o peso final e o ganho de peso dos animais $(\mathrm{P}>0,05)$. Esses resultados concordam com os obtidos por Prado et al. (2000), que encontraram valores médios de 1,36 kg/dia e não obtiveram alteração dessa variável para diferentes níveis de substituição do milho pela polpa cítrica. Os valores aqui obtidos foram mais elevados, mas aqueles autores trabalharam com dietas com cerca de $50 \%$ de concentrado. Por outro lado, Velloso et al. (1974) observaram ganho de peso crescente à medida que se elevou a participação da polpa cítrica, mas em substituição ao milho desintegrado com palha e sabugo. Enquanto os resultados de Henrique et al. (1998) mostraram redução do ganho de peso (de 1,4 para $0,7 \mathrm{~kg} / \mathrm{dia}$ ) com a substituição total do milho em grão pela polpa cítrica, utilizando dietas com $80 \%$ de concentrado. Vale lembrar que esses autores atribuíram a redução do ganho devido ao excesso de cálcio presente na polpa cítrica utilizada, que poderia ter reduzido o consumo e a digestibilidade da proteína bruta e da energia, bem como ter afetado o metabolismo do fósforo, magnésio e outros minerais traços.

O ganho de peso dos animais, não tendo sofrido efeito da participação de polpa cítrica, não afetou a ingestão de matéria seca por dia ou em relação ao peso vivo $(\mathrm{P}>0,05)$. Os valores obtidos para essas variáveis são compatíveis com o tipo de dieta utilizada e a categoria animal empregada, considerando-se o tempo total de confinamento de 113 dias. Essa não alteração do consumo de matéria seca com a inclusão da polpa cítrica também foi observada por Prado et al. (2000), que obtiveram 7,6 kg/dia e 1,9\% do peso vivo. Por outro lado, Velloso et al. (1974) observaram aumento no consumo de matéria seca, à medida que se aumentou a substituição da espiga de milho desintegrada com palha e sabugo pelo milho. Henrique et al. (1998) encontraram diminuição no consumo de matéria seca com a substituição do milho pela polpa cítrica em dietas com $80 \%$ de concentrado, mas o nível de cálcio na polpa cítrica utilizada parece ter sido o fator que limitou o consumo nos tratamentos com esse subproduto.

A eficiência alimentar também não foi afetada $(\mathrm{P}>0,05)$ pela inclusão de níveis crescentes da polpa cítrica. Os resultados encontrados reforçam a indicação do uso de dietas com alto concentrado e de animais de bom potencial de ganho de peso, uma vez que foram necessários 5,2 kg de ração para se obter $1 \mathrm{~kg}$ de

Tabela 3 - Peso inicial, peso final, ganho de peso, ingestão de alimentos e eficiência alimentar dos animais em cada tratamento, com os respectivos coeficientes de variação (CV)

Table 3 - Initial weight, final weight, liveweight gain, food intake and alimentary efficiency of animals in the treatments, with the respective coefficients of variation (CV)

\begin{tabular}{|c|c|c|c|c|c|}
\hline \multirow[t]{2}{*}{$\begin{array}{l}\text { Parâmetros } \\
\text { Parameters }\end{array}$} & \multicolumn{4}{|c|}{$\begin{array}{l}\text { Tratamentos - Porcentagem de polpa cítrica } \\
\text { Treatments - Percentage of citrus pulp }\end{array}$} & \multirow[t]{2}{*}{$\mathrm{CV}^{1}(\%)$} \\
\hline & 0 & 25 & 40 & 55 & \\
\hline $\begin{array}{l}\text { Peso inicial, } \mathrm{kg} \\
\text { Initial weight, } \mathrm{kg}\end{array}$ & 302,63 & 306,43 & 312,43 & 313,18 & 4,36 \\
\hline $\begin{array}{l}\text { Peso final, } \mathrm{kg} \\
\text { Final weight, } \mathrm{kg}\end{array}$ & 439,71 & 452,71 & 450,43 & 454,86 & 3,64 \\
\hline $\begin{array}{l}\text { Ganho de peso, } \mathrm{kg} / \mathrm{dia} \\
\text { Liveweight gain, } \mathrm{kg} / \text { day }\end{array}$ & 1,49 & 1,59 & 1,50 & 1,54 & 8,62 \\
\hline $\begin{array}{l}\text { Ingestão de } \mathrm{MS}^{2}, \mathrm{~kg} / \mathrm{dia} \\
D^{2} \text { intake, } \mathrm{kg} / \text { day }\end{array}$ & 7,94 & 8,16 & 8,17 & 7,73 & 6,53 \\
\hline $\begin{array}{l}\text { Ingestão de } \mathrm{MS}^{2}, \% \text { peso vivo } \\
D M^{2} \text { intake, \% liveweight }\end{array}$ & 2,17 & 2,16 & 2,15 & 2,03 & 6,16 \\
\hline $\begin{array}{l}\text { Eficiência, } \mathrm{kg} \text { ganho } / \mathrm{kg} \mathrm{MS}^{2} \text { ingerida } \\
\text { Efficiency, } \mathrm{kg} \text { gain } / \mathrm{kg} \mathrm{DM}^{2} \text { intake }\end{array}$ & 0,19 & 0,20 & 0,18 & 0,20 & 9,44 \\
\hline
\end{tabular}

$1 \mathrm{CV}$ - Coeficientes de variação (CV - Coefficients of variation).

2 MS - Matéria seca (DM - Dry matter).

R. Bras. Zootec., v.33, n.2, p.463-470, 2004 
ganho de peso. Esses valores são melhores do que os reportados por Prado et al. (2000), que obtiveram $6,3 \mathrm{~kg}$ de matéria seca consumida para cada $\mathrm{kg}$ de ganho de peso, mas da mesma forma não encontraram efeito de níveis de substituição do milho pela polpa cítrica. Por outro lado, Sampaio et al. (1984) observaram que a substituição do milho pela polpa cítrica em 0,50 e $100 \%$, na dieta de bovinos, proporcionou aumento na relação quilograma de matéria seca consumida por quilograma de ganho de peso, de 8,15 para $9,49 \mathrm{~kg}$. Nos resultados obtidos por Loggins et al. (1964), também foi verificada redução linear na eficiência alimentar com a substituição do milho pela polpa cítrica nos níveis de 25, 50, 75 e 100\% da dieta de ovinos em engorda.

Os resultados referentes às características da carcaça, incluindo peso e rendimento de carcaça, espessura de gordura, área de olho de lombo, peso da gordura renal-pélvica-inguinal e do fígado, bem como o pH das fezes, encontram-se na Tabela 4.

Não foram verificados abscessos no fígado de nenhum dos animais, independentemente do tratamento a que foram submetidos. Ressalta-se que, na dieta utilizada neste experimento, além dos $80 \%$ de concentrado, o grão de milho esteve presente em
$40 \%$ da matéria seca da silagem, totalizando $88 \%$ de concentrado.

$\mathrm{O}$ peso final da carcaça quente mostrou efeito linear significativo $(P=0,02)$, tendo sido obtido aumento desse peso com a maior participação da polpa cítrica peletizada na matéria seca da dieta. Houve diferença numérica no ganho de peso dos animais entre tratamentos, apesar de não significativa, mas essa diferença pode ter contribuído para as diferenças encontradas no peso final da carcaça.

O rendimento de carcaça (Tabela 4) não foi afetado pelos níveis de substituição do milho pela polpa cítrica $(\mathrm{P}>0,05)$, com valores inferiores aos encontrados por Prado et al. (2000), que obtiveram rendimento de $57 \%$. Esse menor rendimento de carcaça pode ser explicado, em parte, pela idade de abate dos animais, cerca de 13 meses, e inteiros, enquanto aqueles autores abateram os animais com 20 meses e mestiços Nelore/Angus, sendo essa última raça considerada precoce. Todavia, os resultados obtidos foram muito próximos aos de Henrique et al. (1998), que encontraram $52,4 \%$ de rendimento para animais da mesma raça, idade e nível de concentrado na dieta.

Os níveis de polpa cítrica na dieta afetaram

Tabela 4 - Características da carcaça e pH das fezes dos animais em cada tratamento, com os respectivos coeficientes de variação (CV)

Table 4 - Carcass characteristics and feces $\mathrm{pH}$ of animals in the treatments, with the respective coefficients of variation $(\mathrm{CV})$

\begin{tabular}{|c|c|c|c|c|c|}
\hline \multirow[t]{2}{*}{$\begin{array}{l}\text { Parâmetros } \\
\text { Parameters }\end{array}$} & \multicolumn{4}{|c|}{$\begin{array}{c}\text { Tratamentos - Porcentagem de polpa cítrica } \\
\text { Treatments - Percentage of citrus pulp }\end{array}$} & \multirow[t]{2}{*}{$\mathrm{CV}(\%)$} \\
\hline & 0 & 25 & 40 & 55 & \\
\hline $\begin{array}{l}\text { Peso da carcaça quente }{ }^{1}, \mathrm{~kg} \\
\text { Warm carcass } \text { weight }^{1}, \mathrm{~kg}\end{array}$ & 233,86 & 243,43 & 240,28 & 246,86 & 3,75 \\
\hline $\begin{array}{l}\text { Rendimento de carcaça, \% } \\
\text { Carcass dressing, \% }\end{array}$ & 53,17 & 53,69 & 53,25 & 54,34 & 2,66 \\
\hline $\begin{array}{l}\text { Espessura de gordura }{ }^{2}, \mathrm{~mm} \\
\text { Backfat thickness }^{2}, \mathrm{~mm}\end{array}$ & 7,00 & 6,00 & 5,28 & 4,71 & 31,56 \\
\hline $\begin{array}{l}\text { Gordura renal-pélvica-inguinal, } \mathrm{kg} \\
\text { Kidney, pelvic and inguinal fat, } \mathrm{kg}\end{array}$ & 11,43 & 12,23 & 13,27 & 12,66 & 19,65 \\
\hline $\begin{array}{l}\text { Área de olho de lombo, } \mathrm{cm}^{2} \\
\text { Longissimus muscle area, } \mathrm{cm}^{2}\end{array}$ & 55,94 & 60,18 & 58,06 & 62,03 & 11,87 \\
\hline $\begin{array}{l}\text { Área de olho de lombo, } \mathrm{cm}^{2} / 100 \mathrm{~kg} \text { carcaça } \\
\text { Longissimus muscle area, } \mathrm{cm}^{2} / 100 \mathrm{~kg} \text { carcass }\end{array}$ & 24,11 & 24,96 & 24,13 & 25,21 & 12,12 \\
\hline $\begin{array}{l}\text { Peso do fígado }{ }^{3}, \mathrm{~kg} \\
\text { Liver weight }{ }^{3}, \mathrm{~kg}\end{array}$ & 5,54 & 6,13 & 6,20 & 6,16 & 8,32 \\
\hline $\begin{array}{l}\mathrm{pH} \text { das fezes } \\
\text { Feces } p H\end{array}$ & 6,10 & 5,66 & 5,92 & 5,93 & 7,21 \\
\hline
\end{tabular}

R. Bras. Zootec., v.33, n.2, p.463-470, 2004 
significativamente a espessura de gordura de forma linear $(\mathrm{P}=0,03)$. A espessura de gordura foi reduzida de 7,0 para $4,7 \mathrm{~mm}$ no tratamento sem e com $55 \%$ de polpa cítrica na matéria seca da dieta, significando diminuição de $32 \%$. Na Tabela 1 , pode ser verificada redução da concentração energética estimada da dieta, cerca de 5\%, com o aumento do nível de participação da polpa cítrica, o que pode justificar, pelo menos em parte, essa diminuição da espessura de gordura de cobertura. Vale lembrar que essa estimativa foi a partir da composição dos ingredientes obtida no NRC (1996). A presença da polpa cítrica pode também ter afetado de alguma forma as vias de deposição de gordura, redirecionando-a para outros sítios que não a gordura de cobertura. A espessura de gordura obtida (Tabela 4) foi maior que a encontrada por Henrique et al. (1998), trabalhando com dieta com $80 \%$ de concentrado e milho como componente energético, que obtiveram 4,7 mm. A gordura de cobertura não apresentou diferença significativa no trabalho de Prado et al. (2000), mas os autores apontaram a diferença numérica, acima de $10 \%$, no tratamento em que o milho foi substituído integralmente pela polpa cítrica peletizada (2,7 e 3,6 mm). De qualquer forma, as espessuras de gordura aqui observadas foram suficientes para se considerar uma boa proteção da carcaça durante o resfriamento, mesmo no tratamento com $55 \%$ de polpa cítrica na matéria seca da dieta.

O peso da gordura renal-pélvica-inguinal não foi afetado pelos níveis de substituição do milho pela polpa cítrica peletizada na dieta $(\mathrm{P}>0,05)$, e os valores obtidos (Tabela 4) foram mais que o dobro dos encontrados por Henrique et al. (1998) no tratamento com $80 \%$ de concentrado e milho. Brown \& Johnson (1991) também não encontraram diferença na quantidade de gordura renal-pélvica-inguinal quando substituíram o melaço pela polpa cítrica.

O aumento da participação da polpa cítrica na dieta não afetou a área de olho de lombo $(\mathrm{P}>0,05)$, em tamanho total ou por $100 \mathrm{~kg}$ de carcaça. Esses valores (Tabela 4) foram menores que os obtidos por Prado et al. (2000), que encontraram $82 \mathrm{~cm}^{2}$, e calculando-se por $100 \mathrm{~kg}$ de carcaça, a área de olho de lombo ficou acima de $30 \mathrm{~cm}^{2}$. Com animais da mesma raça e idade do presente trabalho, Henrique et al. (1998) encontraram $54,9 \mathrm{~cm}^{2}$ e $25,9 \mathrm{~cm}^{2} / 100 \mathrm{~kg}$ de carcaça, no tratamento com $80 \%$ de concentrado e milho como componente energético.

$\mathrm{O}$ pH das fezes é, segundo Wheeler \& Noller (1977), um bom indicador da quantidade de amido presente nas fezes. Menor $\mathrm{pH}$ refere-se à maior quantidade de amido nas fezes. Não foram verificadas diferenças entre tratamentos $(\mathrm{P}>0,05)$, e os valores obtidos (Tabela 4) foram inferiores aos obtidos por Henrique et al. (1998), que encontraram 6,62 para dietas com o mesmo teor de concentrado e com a inclusão da polpa cítrica. $\mathrm{O}$ pH das fezes dos animais do tratamento sem polpa cítrica foi semelhante aos obtidos por aqueles autores, com o mesmo tipo de dieta.

De modo geral, os tratamentos não afetaram o desempenho dos animais e as características da carcaça. Assim, a polpa cítrica poderia substituir o milho em grão na composição das dietas, mas essa substituição não deve ser feita apenas na porcentagem da matéria seca; os teores de proteína bruta, energia e minerais devem também ser reajustados.

\section{Conclusões}

A polpa cítrica peletizada pode participar como componente energético em até $55 \%$ da matéria seca da dieta, substituindo o milho em grão, na terminação de tourinhos recebendo dietas com teores elevados de concentrado, uma vez que não houve alteração do desempenho e do rendimento de carcaça.

No acabamento de tourinhos recebendo alto teor de concentrado e mais que $50 \%$ da dieta na forma de polpa cítrica peletizada, é necessário dar atenção à espessura de gordura de cobertura.

\section{Literatura Citada}

BROWN, W.F.; JOHNSON, D.D. Effects of energy and protein supplementation of ammoniated tropical grass hay on the growth and carcass characteristics of cull cows. Journal of Animal Science, v.69, n.1, p.348-357, 1991.

ELANCO. Tylan premix for beef cattle. Indianapolis, IN, 1974. p.4-5. (Technical Bulletin).

ESTEVES, S.N.; MANZANO, A.; NOVAES, N.J. Substituição da espiga de milho desintegrada com palha e sabugo pela polpa de citros peletizada na engorda de bovinos Canchim. Revista da Sociedade Brasileira de Zootecnia, v.16, n.6, p.507-516, 1987.

HENRIQUE, W.; LEME, P.R.; LANNA, D.P.D. et al. Substituição de amido por pectina em dietas com diferentes níveis de concentrado. 1. Desempenho animal e características da carcaça. Revista Brasileira de Zootecnia, v.27, n.6, p.1206$1211,1998$.

LOGGINS, P.E.; AMMERMAN, C.B.; ARRINGTON, L.R. et al. Pelleted rations high in citrus by-products and corn for fattening lambs. Journal of Animal Science, v.27, n.1, p.745, 1964.

NATIONAL RESEARCH COUNCIL - NRC. Nutrient requeriments of beef cattle. 7.ed. Washington, D.C.: 1996. 212p.

R. Bras. Zootec., v.33, n.2, p.463-470, 2004 
PRADO, I.N.; PINHEIRO, A.D.; ALCALDE, C.R. et al. Níveis de substituição do milho pela polpa de citros peletizada sobre o desempenho e características de carcaça de bovinos mestiços confinados. Revista Brasileira de Zootecnia, v.29, n.6, p.2135-2141, 2000. (Suplemento 1)

SAMPAIO, A.A.M.; ANDRADE, P.; OLIVEIRA, M.D.S. et al. Uso de rações com diferentes níveis de proteína e fontes de energia na alimentação de bovinos confinados. Fase II. Revista da Sociedade Brasileira de Zootecnia, v.13, n.4, p.528-534, 1984.

SNIFFEN, C.J.; O'CONNOR, J.D.; VAN SOEST, P.J. et al. A net carbohydrate and protein system for evaluating cattle diets. II. Carbohydrate and protein availability. Journal of Animal Science, v.70, n.11, p.3562-3577, 1992.

STATISTICAL ANALYSIS SYSTEM - SAS. User's guide: statistic. 6.ed. Cary: 1996. 956p.

Van SOEST, P.J. Nutritional ecology of the ruminants. 2.ed. Ithaca: Cornell University Press, 1994. 476p.

VELlOSO, L.; MASOTTI, N.; BECKER, M. et al. Polpa cítrica peletizada para bovinos em confinamento. Revista da Faculdade de Medicina Veterinária e Zootecnia, v.11, p.21-25, 1974.
VIJCHULATA, P.; HENRY, P.R.; AMMERMAN, C.B. et al. Effect of dried citrus pulp and cage layer manure in combination with monensin on performance and tissue mineral composition in finishing steers. Journal of Animal Science, v.50, n.6, p.1022-1030, 1980.

WHEELER, W.E.; NOLLER, C.H. Gastrointestinal tract $\mathrm{pH}$ and starch in feces of ruminants. Journal of Animal Science, v.44, n.1, p.131-135, 1977.

WOODY, H.D.; FOX, D.G.; BLACK, J.R. Effect of diet grain contents on performance of growing and finishing cattle. Journal of Animal Science, v.57, n.3, p.717-726, 1983.

Recebido em: 15/10/02

Aceito em: 11/07/03 